\title{
ARTICLE \\ Laws of nature, natural history, and the description of the world
}

\author{
JAMES W. MCALLISTER \\ Faculty of Philosophy, University of Leiden, The Netherlands
}

\begin{abstract}
The modern sciences are divided into two groups: law-formulating and natural historical sciences. Sciences of both groups aim at describing the world, but they do so differently. Whereas the natural historical sciences produce "transcriptions" intended to be literally true of actual occurrences, laws of nature are expressive symbols of aspects of the world. The relationship between laws and the world thus resembles that between the symbols of classical iconography and the objects for which they stand. The natural historical approach was founded by Aristotle and is retained in such present-day sciences as botany. Modern physics differentiated itself from the natural historical sciences and developed a symbolizing approach at the hands of Galileo and Descartes. Our knowledge of the physical domain is provided by two disciplines: the law-formulating science of physics and a natural historical science on which we depend in the everyday manipulation of our surroundings.
\end{abstract}

\section{Law-formulating and natural historical sciences}

The modern sciences are divided into two groups, defined by the form of the knowledge that they characteristically produce. Sciences of one group characteristically produce knowledge in the form of the "law of nature"-a concise statement of universal scope, frequently expressed as a mathematical equation. Sciences of the other group characteristically produce knowledge in the form of the singular statement (a statement attributing a particular property to an individual place, time, or entity) and the low-level generalization, which may be considered as a conjunction of singular statements.

Modern physics is a science of the first group. Admittedly, physics produces some knowledge in forms other than that of the law of nature: experimental reports and explanatory models, for example. But the law of nature is the most characteristic product of physics, and the achievement that is most highly regarded by physicists. Sciences of the second group include most branches of biological, earth, and engineering science. Although these sciences occasionally formulate statements called laws, such as Mendel's laws and the Hardy-Weinberg law in population genetics (Ruse, 1977, pp. 89-113), the knowledge that they produce is for a much greater part expressed in singular statements and low-level generalizations, such as descriptions of events in 
evolutionary history and of the morphology, physiology, and behaviour of organisms (Mayr, 1985, pp. 53-54).

I shall call sciences of these groups the "law-formulating" and the "natural historical" sciences, respectively. The aim of this paper is to investigate the differences between the outputs of the sciences of these two sorts, and assess their implications for our overall view of science.

Traditionally, two explanations have been offered for the coexistence of natural historical and law-formulating sciences. Auguste Comte (1830-1842, vol. I, pp. 47-95) suggested that the law-formulating phase represents a more advanced stage in the development of a science than the natural historical phase. Every science originates as a natural historical discipline and progresses to formulate laws: physics has already undergone this development, whereas the younger science of biology must still do so. More recently, J. J. C. Smart (1963, pp. 50-61) suggested that the world contains two classes of entities: natural kinds such as chemical elements, which lend themselves to description by universal laws, and historical individuals such as the planet Mars, which lend themselves to description only by singular statements and low-level generalizations. We need sciences of both kinds in order to describe entities of both sorts. I accept neither Comte's nor Smart's explanation, and in this paper will develop an alternative account of the coexistence of the natural historical and law-formulating sciences.

As will already be clear, my usage of the term "law of nature" differs from that of some other writers. For D. H. Mellor (1990, pp. 159-160), for example, a "law of nature" is an objective feature of the world, whereas a statement that describes such a feature is a "law statement". My "law of nature" is what Mellor calls "law statement"; I would choose quite another term-perhaps "phenomenon" or "regularity"-for the feature of the world that such a statement purports to describe. My usage is that of many scientists, who speak of laws of nature as being formulated, tested, and corroborated: such expressions make sense only if laws have the status of statements.

\section{The knowledge-world relationship in the sciences}

Both the law-formulating and the natural historical sciences are regarded by their practitioners and by most philosophers as, in some sense, describing the world. However, the relationships in which the characteristic outputs of the law-formulating and natural historical sciences stand to the world differ. These relationships can be analyzed into aspects that I shall call "extensional" and "intensional".

Under the extensional aspect, the singular statements and low-level generalizations characteristically produced by the natural historical sciences aim to specify nothing other than actual occurrences, i.e. what happens in the world. I do not suggest that these statements contain only observational predicates: the natural historical sciences make probably no less use of theoretical predicates than do any other sciences. Instead, what I claim is that in the natural historical sciences the use to which all predicates - both observational and theoretical-are put is the specification of nothing other than actual occurrences. This feature of the natural historical sciences might initially seem commonplace; but we shall soon see that the law-formulating sciences do not share this aim.

Under the intensional aspect, the statements produced as knowledge by the natural historical sciences are intended to approximate as closely as possible a literally true account of events. In particular, they are intended to render as fully as possible the variety and detail of the world. Of course, no account of finite length will reproduce the 
world in full; but practitioners of the natural historical sciences strive to approach this aim as closely as possible.

Let us now move to the relationship in which laws of nature stand to the world. Take first the extensional aspect. Laws of nature-in so far as they are satisfied at all-are satisfied not only by actual states of affairs, but also by an infinite number of other possible states of affairs. This is because laws of nature state not what there actually is, but rather constraints on what there can be. For instance, laws of nature entail that the universe may contain matter in the liquid state, stable planetary systems, and forms of life; but they do not specify whether our universe is one that actually contains any of these entities.

In fact, successive laws of nature show a decreasing capacity to individuate actual states of affairs from among possible ones. The customary development in physics is for one law of nature to be superseded by another that has wider scope. The statement that the later law has wider scope means that the earlier law can be deduced from a conjunction of the later law and some special assumptions. In turn, this means that the occurrences envisaged as possible by the earlier law form a subset of the occurrences envisaged as possible by the later law. So the later law has a lesser capacity than the earlier law to individuate actual occurrences from among possible ones. For example, Kepler's laws of planetary motion were superseded by Newton's law of gravitation, which has wider scope. Kepler's laws state that the earth moves in an ellipse. As long as the gravitational influence of other bodies is disregarded, Newton's inverse-square law entails that the earth moves in a conic section: an ellipse, a parabola, or a hyperbola. Newton's law thus contains less, not more, information about the actual motion of the earth than do Kepler's laws. There are reasons for preferring Newton's law to Kepler's laws, but its power to identify which possible states of affairs are actual is not one of them.

Lastly, the intensional aspects of laws of nature. As Michael Scriven (1961), Nancy Cartwright (1983, pp. 54-73), and others have noted, while laws of nature may be true of an idealization of phenomena, they are strictly speaking not true of actual occurrences: they are only approximately true of actual occurrences. This claim holds as much for "experimental" laws supposed to be induced from bodies of data, such as Boyle's law of gases, as for "theoretical" laws derived from high-level principles, such as Newton's laws of motion. (The distinction is drawn by, among others, Nagel, 1961, pp. 79-81.)

The claim that laws of nature are not true of actual occurrences does not depend on any particularly scepticist or relativist view of science: on the contrary, it is established by what we call laws of nature themselves. The descriptions of occurrences given by most laws of nature are inconsistent with those of other laws. For example, the description of occurrences given by Newton's law of gravitation is inconsistent with that of Kepler's laws of planetary motion, since, in conjunction with the true statement that the universe contains more than two bodies, Newton's law entails that planets do not move in ellipses; it is inconsistent with that of Galileo's law of free fall, since Newton's law entails that the acceleration of a falling body varies with altitude; and it is inconsistent with that of Einstein's law of gravitation, since, in conjunction with various true statements about the solar system, Einstein's law entails that the perihelion of Mercury precesses at a certain rate. In the light of their logical relations with one another we can rule out, even without consulting empirical data, that all the descriptions of occurrences given by laws are accurate: laws of nature systematically discredit each other as accurate descriptions of occurrences. This is a further respect in which laws of nature 
differ from the low-level generalizations produced by the natural historical sciences, which are designed to be consistent with one another.

Of course, there are partial defences that may be given of laws of nature in regard of the accuracy of their descriptions of occurrences. For instance, one may argue that their descriptions of occurrences are only ever claimed to be true to within a certain limit of approximation, and that this limit is smaller for laws formulated more recently. These claims may be justified. But my intent here is to draw attention to the disparity in the degrees to which the natural historical and the law-formulating sciences attain accuracy of description of occurrences. In the low-level generalizations that they produce, the natural historical sciences consistently attain very high degrees of accuracy in descriptions of occurrences; the characteristic products of the law-formulating sciences, laws of nature, find that standard difficult to match.

\section{In what sense do laws of nature describe the world?}

Thus, while the aim of both the natural historical and the law-formulating sciences is description of the world, the ways in which they set about this task differ. The natural historical sciences discharge the task in a way that may be characterized as straightforward: they record the outcomes of observations, striving to preserve all the detail possible. By comparison, the law-formulating sciences take a cavalier attitude towards detail. They are willing to set aside large amounts of information about actual occurrences - the essence of the accounts of the world produced by the natural historical sciences-in order to formulate expressions that constitute, at best, an approximate description of every member of a set of universes to which ours belongs.

How should this difference between laws of nature and the low-level generalizations produced by the natural historical sciences be reflected in our view of the sciences? Two options suggest themselves. The first is to regard the law-formulating sciences as aiming to describe the world in the same sense as the natural historical sciences, but as accomplishing this task much less well. The second option is to regard the lawformulating sciences as aiming to describe the world in a sense different from the natural historical sciences.

The first of these options is attractively iconoclastic. By portraying natural historical sciences such as botany as more successful than law-formulating sciences such as physics, it inverts Comte's hierarchy. In view of the great value attached to laws of nature, however, I fear that this interpretation overlooks some aspect of them. Laws of nature are among the most highly esteemed products of our culture: they would not have this status if they were merely second-best to low-level generalizations. I therefore incline to the second option, that of regarding the law-formulating sciences as aiming to describe the world in a sense different from the natural historical sciences. As the natural historical sciences demonstrate, the goal of accurate description of occurrences is attained fairly easily, by compiling low-level generalizations about them. If physics and similar sciences persist in formulating laws of nature, which stand to data points in the loose relationship that I have delineated, it must be that accurate recording of occurrences is not their overriding intent. They must, in other words, be aiming at describing the world in some other sense.

In what sense, then, do laws of nature describe the world? The literature offers some standard answers to this question; though, since the question is seldom posed explicitly, the contributions to which I refer are not generally presented as answers to it. 
Among the standard answers are four: that laws of nature describe the world in the sense of providing an inventory of universal regularities; that laws give of the world a modal description, i.e. one that attributes necessity to correlations among events; that laws describe the world in the sense of giving a predictive or projective account of it; and that laws offer explanations of occurrences. I examine these answers in the remainder of this section.

First, the suggestion that laws of nature describe the world in the sense of providing an inventory of universal regularities. According to a popular argument (advanced by, for example, Wigner, 1964, pp. 38-42), the configuration of a physical system at any time is determined jointly by two factors: universal regularities, and the system's configuration at a previous time, or "initial conditions". The specification of initial conditions falls outside the scope of laws of nature - in fact, the initial conditions of physical systems are the typical subject matter of natural historical sciences. But laws of nature can and do describe the universal regularities that the world contains.

This argument presupposes a partition of facts into "facts pertaining to initial conditions" (which lie beyond the scope of laws) and "facts pertaining to regularities" (which laws of nature can be expected to describe). But any partition of facts into these categories is relative to a physical system: what counts as a fact pertaining to initial conditions relative to one system counts as a fact pertaining to regularities relative to another. Consider the following example. It is often said that, while Newton's laws in celestial mechanics can tell us the regularities of the planets' motions (such as the relation between the velocity of a planet and its distance from the sun), it is unfair to ask them the mean radius of the orbit of Mars, say: a parameter such as this, it is explained, depends on the initial conditions of the solar system rather than on universal regularities, and therefore lies beyond the scope of laws of nature. But if we transferred our attention from the solar system to a particular other physical system, we would consider that the orbital parameters of Mars had indeed been determined by universal regularities. This other physical system to which I refer is the protosun, the rotating incandescent mass of gas from which lumps were flung off that cooled and solidified to form the planets. A Newtonian model of that system would allocate facts about the early motion of Mars not to the category of initial conditions, but to the category of (consequences of) universal regularities. After all, on Newtonian theory, every rotating mass of gas with the same physical properties as the protosun would yield a planet having the orbital parameters of Mars.

If there is no standpoint-independent partition of facts into "facts pertaining to regularities" and "facts pertaining to initial conditions", there exists no task "to specify the universal regularities of the world" distinct from the task of recording facts about the world generally. Consequently, the suggestion that laws of nature describe the world in the sense of providing an inventory of universal regularities fails to define a task for laws of nature to discharge.

Second, the suggestion that laws of nature give a modal description of the world, or a description attributing necessity to correlations among events. According to this suggestion, the statement that such-and-such events occur differs from the statement that these events occur necessarily; and a law is a statement of the latter kind. In fact, this claim is untrue. A law of nature does not describe events as occurring as a matter of necessity: it describes events, or at least purports to. It is a particular reading of a law that attributes necessity to the events that the law describes. This may be surmised, if from no other evidence, from the fact that some philosophers offer so-called regularity interpretations of laws (reviewed by Weinert, 1995, pp. 31-39), in which no necessity is 
attributed to correlations among events. So it cannot be said that the description that laws of nature give of the world is intrinsically modal.

Third, the suggestion that laws of nature describe the world in the sense of giving a predictive or projective account of it. This suggestion rests on the belief that laws allow us accurately to predict unobserved occurrences, often extended into a belief that knowledge in the form of laws confers technological mastery over natural phenomena. In reality, laws are not a good source of determinate predictions of actual occurrences, especially by comparison with lower-level generalizations. For one thing, many laws of nature are too indeterminate to predict events. Moreover, this predictive indeterminacy is greatest for laws that are most fundamental - in other words, for the laws that enjoy the greatest esteem among physicists and philosophers. As an example, consider the Dirac equation, which is the description offered by quantum physics of the behaviour of systems of elementary particles. As even Stephen Hawking (1993, pp. 50-51) - who holds laws of nature in high regard-acknowledges, the only system for which the Dirac equation directly yields predictions of any appreciable precision is one of the simplest to which it applies, the hydrogen atom. For systems moderately more complex than the hydrogen atom, such as large molecules, the Dirac equation offers only loose predictions, and only when conjoined with nonlawlike and in some cases nonrigorous assumptions about their behaviour; for systems much more complex than the hydrogen atom, such as the simplest living organisms, the Dirac equation offers no predictions whatever. Where we speak of a prediction being drawn from the Dirac equation, therefore, this prediction in fact usually derives from a compound structure that includes low-level generalizations about systems of elementary particles.

Even clearer is the incapacity of laws of nature to confer mastery over natural phenomena. It is from low-level generalizations such as those of engineering science, rather than laws of nature such as Dirac's equation, that our degree of mastery over natural phenomena derives (Keller, 1984).

Lastly, the suggestion that laws of nature describe the world in the sense of giving explanations of phenomena. This suggestion appears plausible as long as explanation is seen as involving laws: for instance, if explaining an event is seen as inferring a statement describing the event from a lawlike statement, as on the deductive-nomological model. But alternative accounts of explanation attribute no crucial role to laws. For instance, according to the narrative model (Goudge, 1961, pp. 70-79), an explanation is a narrative that sets the explanandum into context, conveying an understanding of how it came to pass. On this model, which coheres with our intuitions about what amounts to a good explanation more closely than the deductive-nomological model, citing a law of nature is neither a necessary nor a sufficient condition for the success of an explanation. This conclusion is borne out by the fact that the natural historical sciences routinely give accounts of events - the extinction of a species or the formation of a volcano, for instance - that involve no laws but constitute intuitively successful explanations.

\section{Laws of nature as expressive symbols of the world}

The standard answers to the question, "In what sense do laws of nature describe the world?", are therefore unconvincing. The alternative answer that I now advance invokes the notion of expressive symbol.

I emphasize from the outset the distinction between expressive and conventional symbols. Conventional symbols, such as " $\pi$ " and " $\mathrm{e}$ " in mathematics, are signs that stand to their objects in a purely arbitrary relation. In contrast, an expressive symbol is 
a sign that depicts some properties of the object for which it stands - or, what amounts $o$ the same thing, depicts that object. The manner of depiction is almost invariably metaphorical rather than literal. Examples of expressive symbols are a symbol of cunning consisting of the picture of a fox and a symbol of mortality consisting of the picture of a bubble. The objects "cunning" and "mortality" are depicted by these symbols, albeit in a metaphorical way, in virtue of the fact that foxes are cunning and bubbles are ephemeral.

Expressive symbols have the following three characteristics, which derive from their definition. First, since a sign must depict properties of an object in order to be an expressive symbol of it, whether a particular sign is a given object's expressive symbol is determined at least partly by matters of fact, namely the properties of the object and of the sign, and not purely by a stipulation. For example, whether a picture of a fox can serve as an expressive symbol of cunning is determined partly by facts about the attribute of cunning and the behaviour of foxes: if foxes behaved as rabbits do, then a picture of a fox would not be an expressive symbol of cunning. My claim that whether something is an appropriate expressive symbol of a given object depends partly on matters of fact is not refuted by the observation that most expressive symbols depict their objects metaphorically rather than literally. After all, whether something is an apt metaphor for an object is also determined partly by matters of fact.

Second, because of this, it is not the case that any sign is as appropriate an expressive symbol of a given object as any other sign. From this it follows that we cannot choose at whim a sign to be the expressive symbol of a given object. For example, a picture of a bubble is not equally adequate an expressive symbol of cunning as a picture of a fox.

Third, since expressive symbols depict properties of their objects, an expressive symbol can convey information about its object: information about an object can be encoded in an expressive symbol by one person and retrieved from it by another. Thus, if a sign is presented to us as an expressive symbol, we can acquire further information about the object for which it stands. In particular, under favourable circumstances, by examining an expressive symbol we can infer for which object it stands. For example, if we are informed that a picture of a fox is an appropriate expressive symbol of a given person (for example, by being told "This person is a fox"), then we can infer some of that person's attributes. Given the metaphorical nature of most expressive symbols, extracting information about an object from an expressive symbol of it generally involves interpreting the symbol as one would a metaphor, rather than straightforwardly reading off the properties of the object.

Further examples of expressive symbols are the personifications of concepts found in classical iconography, such as Iustitia, Cupid, and Mars. A portrayal of Iustitia, with blindfold, balance, and sword, expresses information about the concept of justice, which a beholder of this symbol can extract. The discipline of iconology depends on this fact, as well as on the fact that, consequently, beholders can recognize a given expressive symbol as standing for one object rather than another (Panofsky, 1939; Gombrich, 1965, 1972).

The central claim of this paper is that laws of nature are expressive symbols of the world or of aspects of it, and stand to the world in the way in which other expressive symbols stand to their objects-in the way in which, for example, Iustitia stands to the concept of justice. In support of this claim, I cite the differences between the knowledge-world relationship in the natural historical and law-formulating sciences. A natural historical science aims at compiling a set of propositions that, for every occurrence of a 
given class, includes a proposition that is literally true of that occurrence. Call such a set of propositions a "transcription" of occurrences. There is a one-to-one correspondence between the component propositions of a completed transcription and occurrences of the relevant class. A completed transcription is thus as repetitive and differentiated as the occurrences of which it is a rendering; it is neither intended nor apt to be concise or simple. In contrast, a law of nature is a concise and simple formula that is taken to stand for some feature of the world. It is not, and not required to be, literally true of individual occurrences. Indeed, a law of nature has little internal structure, so there is no possibility of a one-to-one correspondence between constituent parts of it and individual occurrences. Rather, a law captures its object in a global or holistic manner. Examples of laws in which these features are evident are the Schrödinger equation and especially the so-called Schrödinger equation of the universe (Hawking, 1987).

The relationship between laws of nature and the world, which I have just described, closely resembles the relationship between expressive symbols and the objects for which they stand, such as that between Iustitia and justice. An expressive symbol is a concise and simple sign that is taken to stand for some feature of the world. It is not required to shed light on individual instances: for example, Iustitia contains no information about what is just in a particular case. Indeed, like laws of nature, expressive symbols have little internal structure, and are thus unsuited to refer individually to separate occurrences. Rather, a symbol depicts its object in a global or holistic manner. The similarity between laws of nature and expressive symbols cannot be rejected on the grounds that the latter are merely conventional or do not depict objects: as we have seen, expressive symbols differ from conventional symbols precisely in depicting properties of the objects for which they stand.

This account explains the difference between the ways in which we extract information from the output of sciences of the two sorts. The output of the natural historical sciences delivers the information that it contains gradually, upon being scanned progressively; in contrast, a law of nature delivers information in a flash, upon being interpreted according to some key. This is exactly the manner in which an expressive symbol delivers information about its object.

This account explains also the differences in ethos or value system between the natural historical and the law-formulating sciences. The highest value recognized by the natural historical sciences is literal truth about individual occurrences: the fact that pursuit of this value requires accounts of the world to be produced that are increasingly long and intricate is not regarded as an excessive burden. The law-formulating sciences do not hold literal truth about actual occurrences as a high value: conciseness and simplicity rank much more highly. This too accords precisely with what we expect of expressive symbols.

The above analysis should alter our view of concepts, such as "truth" and "explanation", to which we refer in assessing the degree of adequacy of descriptions. Because the relationship in which a successful symbol stands to the world is unlike that in which a successful transcription stands to the world, the properties in virtue of which a law of nature is true or constitutes an explanation cannot be identical to the properties in virtue of which a transcription is true or constitutes an explanation. This view of truth is not relativism: truth may still be absolute within each mode of description. This allows us to explain why the realism-instrumentalism dispute arises more strongly in respect to physics than to, say, biology: the relationship that an expressive symbol has to the world is looser and more metaphorical than that of a transcription. 


\section{The rise of physics as a law-formulating science}

On my view, the modern sciences belong to two groups that describe the world in different senses of the term: in the senses of "transcribing" and "symbolizing" it. What are the origins of this division?

Today's natural historical sciences are descendants of disciplines founded by Aristotle and his immediate followers, by which they believed the world could be investigated scientifically. These disciplines - whose practice must be distinguished from the heavily conceptualist theory of apodeictic or demonstrative science that Aristotle expounded in the Posterior Analytics (Barnes, 1969) - aimed to describe actual occurrences with as much accuracy as possible. They held detail in high respect and mistrusted abstraction and idealization, which divert attention from the description of actual occurrences. This ethos is embodied in, for instance, Aristotelian botany, which was founded by Aristotle's most important direct pupil, Theophrastus of Eresus. This science aimed at providing detailed and accurate descriptions of actual flora, with no abstraction and idealization. The ethos of the science of Theophrastus is maintained in the botany of today.

Aristotle and his immediate followers applied the natural historical approach not only in biological disciplines, but also in the study of inanimate objects. Aristotelian physical science, like Aristotelian botany, aims to describe actual occurrences with as much accuracy and detail as possible, and mistrusts abstraction, idealization, and high levels of generalization.

By the seventeenth century, natural philosophers calling themselves Aristotelian had departed in two respects from the methods used by Aristotle and his immediate followers. First, they envisaged the proper method of natural philosophy no longer as the cautious descriptive procedure of the natural historical approach, but rather as demonstration on the model of the Posterior Analytics. Second, they prescribed that contributions to natural philosophy be judged largely on their accord with the writings of Aristotle and other authorities. Despite these aberrations, many sciences continued to pursue the true natural historical approach in the early seventeenth century (Levine, 1983).

The natural historical approach was not without alternatives: Pythagoras, Plato, and their followers theorized a different manner of describing the world. In their approach, individual actual occurrences were paid less attention: it was more important to capture features of the world as a whole in concise and comprehensive symbols. The many sixteenth-century practitioners of astronomy and mechanics - such as Nicholas Copernicus and Simon Stevin - who depicted the world as manifesting harmonies, symmetries, proportions, and ratios were to a large extent pursuing this symbolizing approach. In the seventeenth century, these vague notions were formalized into the mathematical expressions that would become known as laws of nature. In astronomy, Johannes Kepler progressed from the project of formulating geometrical symbolism of the cosmos in the Mysterium cosmographicum of 1596 to that of formulating mathematical laws of nature in the Astronomia nova of 1609; in mechanics, Galileo Galilei, René Descartes, and others suggested that the aim of accurately describing actual occurrences should be forsaken for the formulation of laws.

Galileo and Descartes recognized that laws of nature would not make accurate descriptions of actual occurrences. I suggested in section 2 that laws of nature are precluded from being good descriptions of actual occurrences by an extensional feature (their compatibility with an indefinitely large number of nonactual occurrences) and an 
intensional feature (their inaccuracy about actual occurrences). Galileo and Descartes recognized these two features of laws of nature explicitly-though, because of their different points of departure, they did not dwell on each equally. Descartes, who proposed that laws of nature be formulated by deduction from more general principles, recognized more clearly the incapacity of laws of nature to individuate actual occurrences from among possible ones:

I must [...] admit that the power of nature is so ample and so vast, and these principles so simple and so general, that I notice hardly any particular effect of which I do not know at once that it can be deduced from the principles in many different ways; and my greatest difficulty is usually to discover in which of these ways it depends on them. (Descartes, 1637, p. 144)

In contrast, Galileo, who proposed to formulate laws of nature by a partly empirical route, perceived more clearly the inaccuracy of laws of nature about actual occurrences. In the Discorsi, the Aristotelian spokesman Simplicio criticizes the concise statements of universal scope produced by Salviati on the grounds that it was "highly improbable that anything demonstrated from such fickle assumptions can ever be verified in actual experiments." Salviati, who is Galileo's mouthpiece, replies:

All the difficulties and objections you advance are so well founded that I deem it impossible to remove them. For my part, I grant them all, as I believe our Author would also concede them. I admit that the conclusions demonstrated in the abstract are altered in the concrete, and are so falsified that horizontal [motion] is not equable; nor does natural acceleration occur [exactly] in the ratio assumed; nor is the line of the projectile parabolic, and so on. (Galileo, 1638 , p. 223; interpolations by Drake)

The diffidence of Galileo and Descartes towards actual occurrences is amply justified: actual occurrences are in markedly closer agreement with the output of Aristotelian physics than with that of Galilean or Cartesian physics. For instance, the free fall of bodies under everyday conditions near the surface of the earth and the movement of objects against friction are described more accurately by Aristotelian accounts, which are alert to the effects of the weight and shape of bodies, than by Galileo's laws (Feinberg, 1965; Adler \& Coulter, 1975). While they recognized the shortcomings of laws of nature as descriptions of actual occurrences, Galileo and Descartes did not regard these shortcomings as nullifying the value of laws. This is because they regarded a law of nature as expressing a truth not of actual occurrences, but of an aspect of nature (which they sometimes called "phenomenon") in its entirety in symbolic form.

Since the sources of empirical evidence that were then canonical-straightforward reports of actual occurrences - tended to support Aristotelian accounts of the physical world sooner than their own, the advocates of the law-formulating approach were compelled to justify their laws by other means. They first cast doubt on the worth of observations of actual occurrences. Galileo insisted that esperienze of actual occurrences were untrustworthy as sources of knowledge unless they were sensate, or heavily idealized (Koertge, 1977); Descartes enrolled scepticism to suggest that actual occurrences are what we know least well, if by "knowledge" we mean the apprehension of something that he called "clear and distinct ideas" (Sakellariadis, 1982). According to these arguments, the manifest incapacity of laws to recover everyday experience is not a reason for dissatisfaction with them. 
In place of reports of actual occurrences, the advocates of the law-formulating approach proposed experiment as a new source of evidence in science. In Aristotelian natural philosophy, experimentum had denoted nothing more than an experience of something. Practitioners of the law-formulating approach redefined the term to denote a trial that differed from everyday experience in two respects: the contrived circumstances of its occurrence and the convention that its outcome may be reported selectively. Where even experiments failed to support laws of nature, advocates of the law-formulating approach turned to sources of justification still further removed from everyday experience: Galileo claimed that laws of mechanics could be established by thought experiment (McAllister, 1996), while Descartes argued that the attributes of God assured us of the truth of his laws of optics.

The question remains why Galileo, Descartes, and others resolved to found a discipline of this new type. The suggestion that knowledge of the world may take the form of compact symbols that stand to phenomena in a global or holistic relation, and whose construction does not require meticulous acquaintance with actual occurrences, can have great charm. This charm would act more powerfully on thinkers persuaded, as by Neoplatonism, that actual occurrences are an only imperfect reflection of some underlying reality, and that fundamental knowledge is knowledge of this underlying reality rather than of occurrences (Koyré, 1968, pp. 16-43).

Following its inauguration in mechanics, the law-formulating approach spread gradually to other branches of physical science. For instance, investigations of electricity adopted the law-formulating approach in the $1780 \mathrm{~s}$, with the enunciation of such formulae as Coulomb's law of electrostatic attraction.

\section{The coexistence of natural historical and law-formulating sciences}

The fact that we possess many laws of nature relating to physical phenomena has fostered the belief that the entirety of our present-day scientific knowledge about the physical domain is supplied by the law-formulating science of modern physics. This belief is supported by historians of the scientific revolution, who generally portray the rise of the law-formulating approach as a reform of physics, after which physicists ceased to practise the natural historical version of the discipline.

This belief is far from the truth. In fact, we retain today very extensive knowledge about the physical world in the form of natural history. Especially important is our knowledge in the form of singular statements and low-level generalizations about the physical apparatus with which we deal, both in homely surroundings and in the practice of experimental physics. This body of knowledge derives, I suggest, from a natural historical science about the physical world, distinct from physics. After all, the ethos and output of this discipline are quite unlike those of physics. In common with all other natural historical sciences, this discipline attaches the highest value to accuracy of description about actual occurrences in full reflection of their variety; it regards knowledge in the form of laws of nature-rightly - as too theoretical and academic to be applicable in any realistic sense. This discipline closely resembles the science that was called "physics" before this name was appropriated by Galileo and Descartes for their law-formulating science of the physical domain. Indeed, this discipline holds to many of the claims of Aristotelian physics (Clement, 1983): in this discipline it counts as knowledge, for instance, that bodies of different weights and shapes near the surface of the earth fall at different speeds under gravity, and that it is generally necessary to continue to apply a force to a body if it is to remain in a state of motion. 
The existence of this natural historical science of the physical domain is frequently overlooked, because of its low visibility and intellectual status: it is practised not by theoreticians, but by laboratory technicians, engineers and householders, and its output is seldom recorded in writing (Shapin, 1989). Nonetheless, this discipline is essential for our interaction with the physical world and indeed for the practice of law-formulating physics.

Law-formulating and natural historical sciences coexist in other domains too. I suggest that for every domain for which there is a law-formulating science, there exists also a natural historical science-though the term "science" is generally applied only to the former. I suggest that this is the best way to interpret, for instance, the current controversy about the existence of a folk psychology alongside a nascent psychological science (Wilkes, 1991): the former is a natural historical discipline on which we rely in actual interactions with other people, while the latter is an intendingly law-formulating discipline inspired by modern physics. Similarly, historiography may be practised as a law-formulating discipline, as it is by Marxist historians, who formulate general principles of political evolution that may or may not be precisely instantiated in the development of a particular country; or as a natural historical discipline, as it is by the Annales school, in which grand generalization is sacrificed for detailed knowledge of circumscribed periods.

These observations suggest that a biological science of which the output consists of laws of nature - a law-formulating counterpart to present-day biology-may not be unthinkable. Such a discipline would be dedicated to symbolizing aspects of the organic world rather than giving detailed transcriptions of occurrences. This may sound like a strange undertaking, but in fact the symbolizing approach has occasionally been practised in the biological sciences. In the seventeenth century much effort was devoted to constructing emblems of biological entities (Ashworth, 1990); and Romantic biology aimed not to give accurate morphological descriptions of individual organisms, as does mainstream taxonomy, but to identify the Bauplan or Urtyp of large classes of organisms, such as the vertebrates (Lenoir, 1987, pp. 21-24). I suggest that these notions are best seen as standing in a symbolic relationship to actual occurrences, and thus as analogous to laws of nature.

If my account is accurate, then neither Comte's nor Smart's view of the division between the law-formulating and the natural historical sciences can be endorsed. Natural historical sciences are not sciences less advanced than law-formulating sciences, as Comte held: on the contrary, sciences of the two sorts describe the world in different ways, and should not be expected to evolve into one another. Nor is the choice between practising a law-formulating and a natural historical science dictated by the subject matter, as Smart suggested: a science of either sort may be practised in any domain.

\section{Acknowledgements}

I presented previous versions of this paper at a seminar at the Department of Philosophy, Stanford University, in April 1995; at the tenth International Congress of Logic, Methodology and Philosophy of Science, Florence, in August 1995; at the twentysecond annual Philosophy of Science Conference, Inter-University Centre, Dubrovnik, in April 1996; and at a workshop at the Centre for the Philosophy of the Natural and Social Sciences, London School of Economics, in June 1996. I thank the participants for their comments. 


\section{References}

Adler, C.G. \& Coulter, B.L. (1975) Aristotle: villain or victim?, Physics Teacher, 13, pp. 35-37.

AshworTH, W.B. (1990) Natural history and the emblematic world view, in: D.C. LINDBERG \& R.S. Westman (Eds), Reappraisals of the Scientific Revolution (Cambridge, Cambridge University Press), pp. 303-332.

Barnes, J. (1969) Aristotle's theory of demonstration, Phronesis, 14, pp. 123-152.

Cartwright, N. (1983) How the Laws of Physics Lie (Oxford, Clarendon Press).

Clement, J. (1983) A conceptual model discussed by Galileo and used intuitively by physics students, in: D. GentNer \& A.L. STEvens (Eds), Mental Models (Hillsdale, N.J., Lawrence Erlbaum Associates), pp. 325-340.

СомтE, A. (1830-1842) Cours de philosophie positive. Six vols. Reprinted as vols I-VI of Oeuvres d'Auguste Comte. Twelve vols (Paris, Anthropos, 1968-1971).

Descartes, R. (1637) Discourse on the Method. Translated in: J. CotTingham, R. Stoothoff, D. Murdoch \& A. KenNY (Eds), The Philosophical Writings of Descartes. Three vols. (Cambridge, Cambridge University Press, 1984-1991), vol. I, pp. 111-151.

Fennberg, G. (1965) Fall of bodies near the earth, American fournal of Physics, 33, pp. 501-502.

GalileI, G. (1638) Two New Sciences. Translated by S. Drake (Madison, University of Wisconsin Press, 1974).

Gombrich, E.H. (1965) The use of art for the study of symbols, American Psychologist, 20, pp. 34-50.

Gombrich, E.H. (1972) Symbolic Images: Studies in the Art of the Renaissance (London, Phaidon).

Goudge, T.A. (1961) The Ascent of Life: A Philosophical Study of the Theory of Evolution (Toronto, University of Toronto Press).

HAWKING, S. (1987) The Schrödinger equation of the universe, in: C.W. KILMISTER (Ed.), Schrödinger: Centenary Celebration of a Polymath (Cambridge, Cambridge University Press), pp. 176-179.

HawkIng, S. (1993) Black Holes and Baby Universes and Other Essays (London, Bantam Books).

Keller, A.G. (1984) Has science created technology?, Minerva, 22, pp. 160-182.

Kozrtge, N. (1977) Galileo and the problem of accidents, fournal of the History of Ideas, 38, pp. 389408.

Koyré, A. (1968) Metaphysics and Measurement: Essays in Scientific Revolution (London, Chapman and Hall).

LENOIR, T. (1987) The eternal laws of form: morphotypes and the conditions of existence in Goethe's biological thought, in: F. AMRINE, F.J. ZuCKER \& H. WHEELER (Eds), Goethe and the Sciences: A Reappraisal (Dordrecht, Reidel), pp. 17-28.

LEVINE, J.M. (1983) Natural history and the history of the scientific revolution, Clio, 13, pp. 57-73.

MAYR, E. (1985) How biology differs from the physical sciences, in: D.J. DePEw \& B.H. WEBER (Eds), Evolution at a Crossroads: The New Biology and the New Philosophy of Science (Cambridge, MA., MIT Press), pp. 43-63.

MCAllister, J.W. (1996) The evidential significance of thought experiment in science, Studies in History and Philosophy of Science, 27, pp. 233-250.

Mellor, D.H. (1990) Laws, chances and properties, International Studies in the Philosophy of Science, 4, pp. $159-170$.

NAGEL, E. (1961) The Structure of Science: Problems in the Logic of Scientific Explanation (London, Routledge and Kegan Paul).

PANOFsky, E. (1939) Studies in Iconology: Humanistic Themes in the Art of the Renaissance (New York, Oxford University Press).

RuSE, M. (1977) Is biology different from physics?, in: R.G. ColodNY (Ed.), Logic, Laws, and Life: Some Philosophical Complications (Pittsburgh, PA., University of Pittsburgh Press), pp. 89-127.

SAKellariadis, S. (1982) Descartes's use of empirical data to test hypotheses, Isis, 73, pp. 68-76.

SCRIVEN, M. (1961) The key property of physical laws-inaccuracy, in: H. FEIGL \& G. MAXWELL (Eds), Current Issues in the Philosophy of Science (New York, Holt, Reinhart and Winston), pp. 91-101.

ShapIN, S. (1989) The invisible technician, American Scientist, 77, pp. 554-563.

Smart, J.J.C. (1963) Philosophy and Scientific Realism (London, Routledge and Kegan Paul).

WEINERT, F. (1995) Laws of nature-laws of science, in: F. WEINERT (Ed.), Laws of Nature: Essays on the Philosophical, Scientific and Historical Dimensions (Berlin, De Gruyter), pp. 3-64.

WigNer, E.P. (1964) Events, laws of nature, and invariance principles, in: E.P. Wigner, Symmetries and Reflections: Scientific Essays (Bloomington, Indiana University Press, 1967), pp. 38-50.

WILKES, K.V. (1991) The relationship between scientific psychology and common-sense psychology, Synthese, 89 , pp. 15-39. 


\section{Note on contributor}

James W. McAllister is University Lecturer in the Faculty of Philosophy, University of Leiden. He is the author of Beauty and Revolution in Science (Ithaca, N.Y., Cornell University Press, 1996), and coeditor of The Question of Style in Philosophy and the Arts (Cambridge, Cambridge University Press, 1995). He held a Visitorship at the Institute for Advanced Study, Princeton, in the second semester of 1996-1997. Correspondence: Faculty of Philosophy, University of Leiden, P.O. Box 9515, 2300 RA Leiden, The Netherlands. 